Maria Julia Ajejas Bazán ${ }^{1,2}$ Carlos Fuentes Mora ${ }^{2}$

\title{
Compliance with preventive measures against malaria of personnel treated in the centre of international vaccination of the Minister of Defence (Spain)
}

'Complutense University. Faculty of Nursing, Physiotherapy and Podiatry. Nursing Department. Madrid. Spain.

${ }^{2}$ Preventive Medicine Institute. Defense Ministry. Madrid. Spain.

\section{Article history}

Received: 8 August 2019; Revision Requested: 9 0ctober 2019; Revision Received: 1 December 2019; Accepted: 10 December 2019; Published: 22 January 2020

\section{ABSTRACT}

Objective. This study evaluated the compliance with preventive measures against malaria of the personnel treated in the Spanish Defence International Vaccination Centre (CVI).

Material and methods. A retrospective study was conducted from November to December 2017. The population was 534 individuals. All were treated in CVI, prior to their deployment on endemic areas of malaria, with prevention measures type $C$ and D. A questionnaire of 23 items was elaborated.

Results. The percentage of response to the questionnaire was $36.9 \%(n=194), 100 \%$ were male. Air conditioner was the most used protection measure 93.8\% (IC 95\% 90.4-97.2). Only 35.5\% (95\% Cl: 28.8-42.2) of them, showed good adherence to medication. The factors that influenced in the adherence were the country and the length of deployment. It was not established a direct relationship between the occurrence of adverse reactions and low adherence to treatment.

Conclusions. The general protection measures against malaria were met in a high percentage, whilst the use of chemoprophylaxis was very low. These epidemiological data allowed us to know the validity of the health education that is provided in the traveller's care consultation. It also allowed being aware of the possibilities of infection and import of malaria by personnel of the Spanish Armed Forces. The traveller's office will reinforce the importance of taking the adequate chemoprophylaxis trough conferences and informative diptychs.

Keywords: Preventive measures, Malaria, Chemoprevention, Adverse Reactions, Mosquito Vectors

Correspondence:

Maria Julia Ajejas Bazán.

Complutense University. Faculty of Nursing, Physiotherapy and Podiatry. Nursing Department. Madrid. Spain.

E-mail:majejas@ucm.es.
Cumplimiento de las medidas preventivas contra la malaria, del personal tratado en el centro de vacunación internacional del Ministerio de Defensa (España)

\section{RESUMEN}

Objetivo. Este estudio evaluó el cumplimiento de las medidas preventivas contra la malaria por parte del personal tratado en el Centro de Vacunación Internacional de la Defensa.

Material y métodos. Se realizó un estudio retrospectivo de noviembre a diciembre de 2017. La población era de 534 individuos. Todos fueron tratados en el Centro de Vacunación Internacional, antes de su despliegue en áreas endémicas de malaria, en las que según indicación de la Organización Mundial de la Salud se recomendaba el uso de medidas de prevención tipo C y D. Se elaboró un cuestionario de 23 items.

Resultados. El porcentaje de respuesta al cuestionario fue del 36,9\% ( $n=194)$, el 100\% eran hombres. El aire acondicionado fue la medida de protección más utilizada 93,8\% (IC 95\% 90,4-97,2). Solo el 35,5\% (IC 95\%: 28,8-42,2) de ellos, mostraron buena adherencia a la medicación. Los factores que influyeron en la adhesión fueron el país y la duración del despliegue. No se estableció una relación directa entre la aparición de reacciones adversas y la baja adherencia al tratamiento.

Conclusiones. Las medidas generales de protección contra la malaria se cumplieron en un porcentaje elevado, mientras que el uso de quimioprofilaxis fue bajo. Estos datos epidemiológicos nos permitieron conocer la validez de la educación sanitaria que se brinda en la consulta de atención al viajero. También permitió conocer las posibilidades de infección e importación de malaria por parte del personal de las Fuerzas Armadas Españolas. La oficina del viajero reforzará la importancia de una quimioprofilaxis adecuada a través de conferencias y dipticos informativos.

Palabras clave: Medidas preventivas, Quimioprofilaxis, Malaria, reacciones adversas, vector Mosquito 


\section{INTRODUCTION}

Malaria is a disease caused by a parasite of the genus Plasmodium, transmitted by the female Anopheles mosquito. It is an important cause of morbidity and mortality worldwide, despite being preventable and able to be cured [1, 2]. According to WHO data in 2015, 212 million cases were diagnosed, which, according to estimates, cost 429,000 lives [3]. The intensification of prevention and control measures has resulted in a reduction in malaria mortality rates of more than $60 \%$ worldwide, compared to the rates recorded in 2000. Sub-Saharan Africa remains the area reporting a highest number of the global burden. In 2016, the region accounted for $89 \%$ of malaria cases and $91 \%$ of deaths due to this cause $[3,4]$. Military personnel are considered a high risk group, due to their deployment in operations in tropical and subtropical zones, where there is a high risk of malaria transmission and sometimes a low risk perception, little adherence to protection measures and extensive exposure times to arthropod bites $[5,6]$. The implemented preventive measures are divided into four groups: general measures (such as the use of long-sleeved clothing and long pants), physical measures (such as the use of air conditioner and mosquito nets), use of insect repellent, and finally, antimalarial chemoprophylaxis [7]. In the traveller's office of the Institute of Preventive Medicine of the Defence, the health advice and the recommended vaccines are prescribed, administered and facilitated according to the area of deployment. Likewise, in relation to antimalarial chemoprophylaxis, Atovaquone-Proguanil is recommended as the first-line drug, as scientific evidence shows less adverse reactions and greater adherence to treatment [8-10]. Among the adverse reactions described by the technical sheet, the most frequent are: headache, abdominal pain and diarrhoea [11]. Currently there are not studies, neither data about the degree of compliance of the measures established in the Spanish Defence International Vaccination Centre (CVI) to protect the personnel from malaria. These circumstances justify the relevance of conducting this study.

The main aim was to know the degree of compliance with the preventive measures against malaria, of the personnel attended in the CVI of the defence. The secondary aims were: (i) to evaluate the extent of compliance with measures to prevent mosquito bites: general measures, physical measures, use of repellent, and to determine the adherence to chemoprophylaxis malaria; (ii) to describe the occurrence of Adverse Drugs Reactions (ADRs) associated with its consumption; (iii) to establish whether there is a relationship between the occurrence of adverse reactions and the low adherence to treatment; and (iv) to establish whether there is a relationship between the duration of chemoprophylaxis and the increase in adverse reactions.

\section{MATERIAL AND METHODS}

A retrospective study was conducted from November to December 2017. The population was 534 individuals. All were treated in $\mathrm{CVI}$, prior to their deployment on endemic areas of malaria, with prevention measures type $C$ (Exists risk of transmission of malaria by Plasmodium falciparum and chloroquine resistance and sulfadoxine/pyrimethamine, so military personnel had to take general prevention measures against mosquito bites and chemoprophylaxis with atovaquone-proguanil, or doxycycline or mefloquine (the choice is in role of reported side effects and of the contraindications) and type $D$ (There is a risk of malaria due to $P$. falciparum, in combination with multiple resistance to antimalarial medications, so military personnel had to take general prevention measures against mosquito bites and mefloquine or doxycycline or atovaquone-proguanil (select according to pattern of reported resistance, side effects press releases and contraindications) [12]. A questionnaire of 23 items was elaborated.

The inclusion criteria were:

- Military personnel, Guardia Civil and civil personnel assigned to the Ministry of Defense (MOD) that had been treated in the CVI during the period between September 2016 and September 2017.

- Personnel deployed to malaria endemic areas with type $C$ and D prevention measures and Atovaquone-Proguanil as antimalarial chemoprophylaxis.

- Health advice has been received to prevent mosquito bites.

- Age $\geq 18$ years.

- Male and female.

- Weight $\geq 40 \mathrm{~kg}$, according to the drug's data sheet, it is not recommended to administer atovaquone-proguanil for people whose body weight is lower than the aforementioned.

The sample size was calculated taking into account a 5\% error, a confidence level of $95 \%$ and a loss percentage of $15 \%$. A sample of 173 individuals was obtained.

A questionnaire of 23 items was elaborated with an interrogatively and assertively style. The validation of that questionnaire was carried out with the first 20\% of responses received. In addition, an item was included, asking their acceptance to participate in the study and their informed consent. The rest were the variables to be measured previously described.

The first week of November 2017 a questionnaire was sent by email to the selected staff, who fulfilled the inclusion criteria. An informative letter explaining the objectives of the study was attached to the mail. Upon receipt, all personal information of the questionnaire was deleted to preserve the anonymity. Two weeks after the initial send of emails, a reminder of participation was sent. After four weeks of the initial send of emails, the inclusion of questionnaires in the database was completed.

Statistical analysis. It was described by absolute and relative frequencies. To assess whether there was a statistically significant association $(p<0.05)$ of the dependent variable with each of the independent variables, a bivariate analysis was performed using the Pearson Chi-Squared Test. The corresponding confidence interval (ICs 95\%) was calculated. A 
multivariate analysis was carried out to determine which variables contributed to adherence to preventive measures. The treatment of the data was tabulated and analysed using the statistical package SPSS 21.0 for Windows.

Ethics. Regarding the ethical aspects of the investigation, the provisions of current legislation were respected. The project was presented to the Drug Research Ethics Committee (CEIm) of the Central de la Defensa Hospital (reference 64/17), where it was certified that the study followed the requirements and ethical postulates. Likewise, the data was treated confidentially in accordance with Spanish law (Organic Law 15/1999, of December 13, Personal Data Protection).

\section{RESULTS}

The study population were 534 individuals, 489 (91.6\%) were male and $45(8.4 \%)$ female. $10.6 \%$ had $\leq 10$ years of active time, $18.2 \%$ between $11-20$ years, $29.8 \%$ between 21 30 years and $41.4 \%>$ of 30 years. About $1.7 \%$ of the total referred to have completed only Level 1/2 education, $42.2 \%$ A-level education and $56.1 \%$ Higher Education. In relation with their branches, 30.2\% belonged to the Army, 15.5\% to the Air Forces, $4.9 \%$ to the Navy, $8.4 \%$ to the MOD, 39.1\% to the Guardia Civil and 1.9\% to the UME and civil personnel assigned to the MOD. A $4.9 \%$ reported having been deployed to Somalia, $2.8 \%$ to Central African Republic, $5.4 \%$ to Mauritania, $29.2 \%$ to Mali, $10.3 \%$ to Gabon, $11.8 \%$ to Djibouti, $21.3 \%$ to Dakar, $9.0 \%$ to Afghanistan and others 5.3\%. Of the total, $28.2 \%$ were deployed $<1$ month, $48.1 \%$ between 1 and $<6$ months, $15.4 \% 6$ months and $8.3 \%>$ of 6 months. In addition, $71.6 \%$ reported not taking any medication. All of them were treated at the CVI between September 1, 2016 and September 30, 2017. Everyone travelled to an endemic area of malaria, where the WHO recommends type $\mathrm{C}$ and D prevention measures.

A $36.9 \%$ response to the questionnaire provided was obtained $(n=194), 100 \%$ were male (none female were included), and $7.2 \% \mathrm{had} \leq 10$ years of active time, $23.2 \%$ between 11 20 years, $27.8 \%$ between $21-30$ years and $41.8 \%>$ of 30 years (increased the percentage of individuals between 11-20 years compared to the population, decreasing those who had less active time). About $2.6 \%$ of the total referred to have completed only Level $1 / 2$ education, $37.1 \%$ A level education and $60.3 \%$ Higher Education (Samples studies level were similar to the population). In relation with their branches, $22.2 \%$ belonged to the Army, $17.5 \%$ to the Air Forces, $5.2 \%$ to the Navy, $7.7 \%$ to the MOD, $45.9 \%$ to the Guardia Civil and 1.5\% to the UME and civil personnel assigned to the MOD (participated more Guardia Civil regarding the population). A 5.7\% reported having been deployed to Somalia, 2.1\% to Central African Republic, 4.6\% to Mauritania, 28.9\% to Mali, $11.3 \%$ to Gabon, 9.8\% to Djibouti, 18.0\% to Dakar, 8.2\% to Afghanistan and others 11.3\% (the percentage of people who participated in the different countries was similar in the sample and population). Of the total, $26.0 \%$ were deployed $<1$ month, 40.2\% between 1 and $<6$ months, 17.7\% 6 months and $16.1 \%>$ of 6 months. In addi-

\begin{tabular}{l|ccc}
\hline Table 1 & \multicolumn{3}{l}{$\begin{array}{l}\text { Degree of compliance with individual } \\
\text { protection measures }\end{array}$} \\
\cline { 2 - 4 } & \multicolumn{3}{c}{ Degree of compliance } \\
\hline Air conditioner & $182(93.8)$ & $(90.4-97.2)$ & 0.058 \\
Mosquito screens on windows & $108(56.0)$ & $(49.0-63.0)$ & 0.025 \\
Mosquito nets for bed & $67(34.0)$ & $(27.3-40.7)$ & 0.039 \\
Use of insect repellent & $168(85.8)$ & $(80.9-90.7)$ & 0.098 \\
Chemoprophylaxis & $37(19.0)$ & $(13.5-24.5)$ & 0.076 \\
\hline
\end{tabular}

tion, 68.9\% reported not taking any medication. All the results presented in this study referred to the personnel who responded to the questionnaire. A bivariate analysis was also carried out between the personnel who answered the questionnaire and those who did not, finding no statistically significant association $(p=0.136)$.

In relation to the degree of compliance with personal preventive measures, air conditioner was the most used protection measure 93.8\% (IC 95\% 90.4-97.2) (table 1).

One influential factor was the educational level. Staff with higher education made more use of air conditioner (56.1\%) than those with a lower level (2.6\%). The same happened with the use of mosquito screens on windows, with a bigger use in those with higher education (33.7\%) compared to personnel with Level 1/2 education (2.6\%). Regarding the use of mosquito nets for beds, it was (22.3\%) for personnel with higher education, compared with (0.0\%) of personnel with Level $1 / 2$ education. Being statistically significant the association ( $p=$ $0.036, p=0.02$ and $p=0.027$ respectively) (table 2 ).

The Guardia Civil was the most numerous group that made use of air conditioner (42.8\%), followed by the Army (20.6\%). It was also the Guardia Civil the bigger group using mosquito screens in windows (28.9\%) and mosquito nets for beds (15.7\%). Statistically, there was only a significant association in the use of mosquito screens for windows and mosquito nets for beds ( $p=0.02, p=0.035$ respectively) (table 2 ).

The country of deployment, where physical measures of protection were most used, was Mali (air conditioner 27.8\%, screen for windows 28.0\% and net for beds 22.3\%); there is only a statistically significant association in the use of nets for windows and beds $(p<0.01)$ (table 2).

In relation to the length of the deployment, the shorter the stay, the more they used mosquito screens for windows $(<1$ month $(18.1 \%)>6$ months $(12.8 \%))$ and beds $(<1$ month $(9.4 \%)>6$ months $(8.9 \%))$. A statistically significant association was found in both cases ( $p=0.01, p=0.027$ respectively) (table 2).

The country where the insect repellent was most used was Mali (26.9\%) and the country with a higher antimalarial chem- 


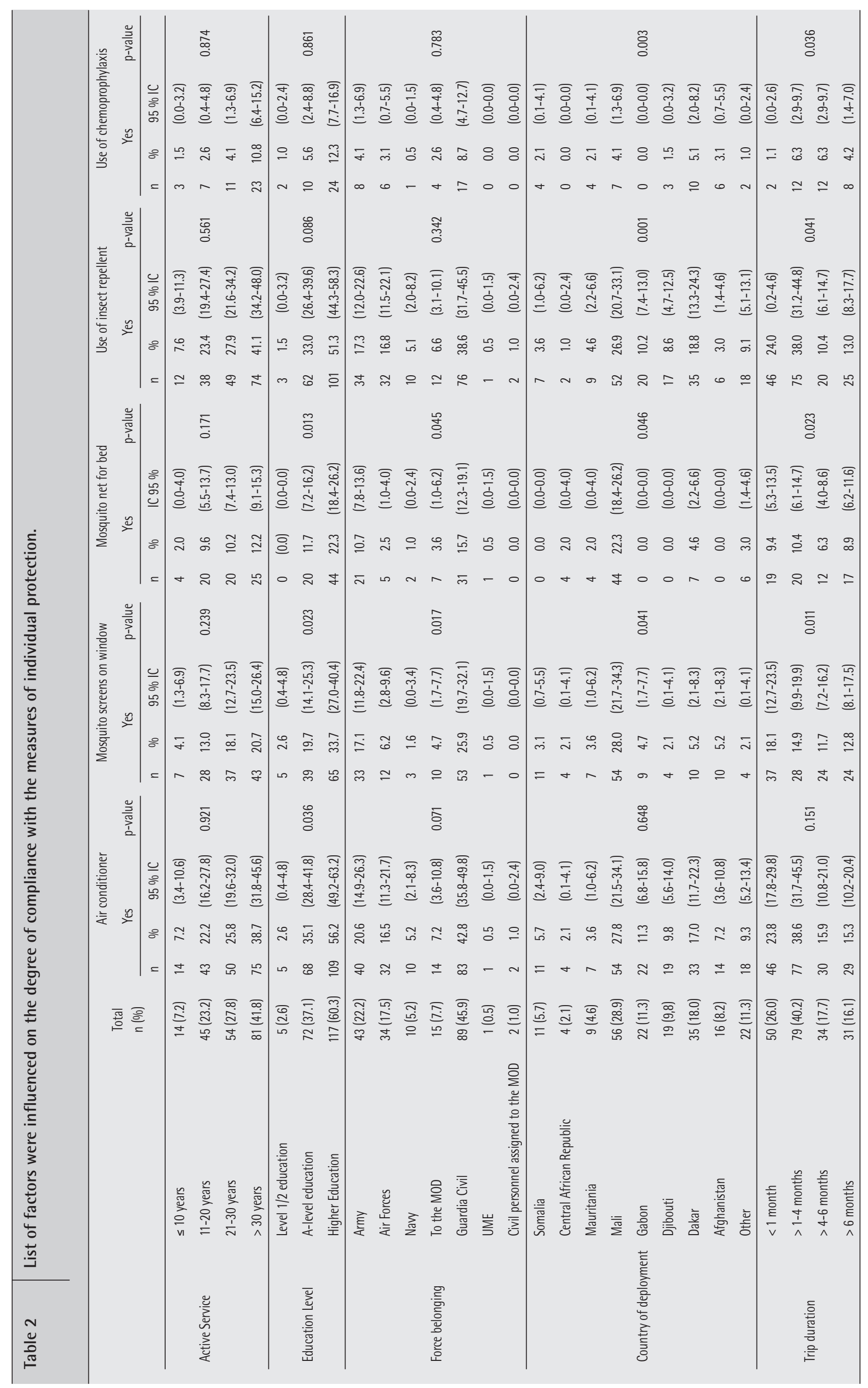




\begin{tabular}{|c|c|c|c|c|c|}
\hline \multirow[t]{3}{*}{ Table 3} & \multicolumn{5}{|c|}{$\begin{array}{l}\text { Multivariate analysis of temporal trends } \\
\text { and associated factors. }\end{array}$} \\
\hline & & \multicolumn{2}{|c|}{ Mosquito screens on window } & \multicolumn{2}{|c|}{ Mosquito net for bed } \\
\hline & & OR & (IC $95 \%)$ & OR & (IC $95 \%)$ \\
\hline \multirow{4}{*}{ Active Service } & $\leq 10$ years & 1.87 & $(1.68-1.99)$ & 1.62 & $(1.55-1.69)$ \\
\hline & $11-20$ years & 1.4 & $(1.21-1.60)$ & 1.38 & $(1.30-1.46)$ \\
\hline & $21-30$ years & 1.01 & $(0.99-1.03)$ & 1.05 & $(0.97-1.09)$ \\
\hline & $>30$ years & 1 & & 1 & \\
\hline \multirow{3}{*}{ Education Level } & Level $1 / 2$ education & 1.24 & $(1.07-1.42)$ & 1.37 & $(1.21-1.54)$ \\
\hline & A-level education & 1.17 & $(1.05-1.30)$ & 1.11 & $(1.03-1.20)$ \\
\hline & Higher Education & 1 & & 1 & \\
\hline \multirow{7}{*}{ Force Belonging } & Army & 1.49 & $(1.34-1.64)$ & 1.43 & $(1.33-1.53)$ \\
\hline & Air Forces & 1.42 & $(1.36-1.59)$ & 1.41 & $(1.38-1.57)$ \\
\hline & Navy & 1.36 & $(1.21-1.52)$ & 1.31 & $(1.29-1.33)$ \\
\hline & To the MOD & 1.28 & $(1.05-1.35)$ & 1.27 & $(1.11-1.35)$ \\
\hline & Civil Personnel & 1.23 & $(1.11-1.35)$ & 1.2 & $(1.18-1.22)$ \\
\hline & UME & 1.22 & $(1.09-1.39)$ & 1.1 & $(1.09-1.11)$ \\
\hline & Guardia Civil & 1 & & 1 & \\
\hline \multirow{4}{*}{ Trip duration } & $<1$ month & 1.36 & $(1.21-1.52)$ & 1.68 & $(1.58-1.78)$ \\
\hline & $>1-4$ months & 1.22 & $(1.09-1.39)$ & 1.32 & $(1.22-1.42)$ \\
\hline & $>4-6$ months & 1.01 & $(0.92-1.1)$ & 1.11 & $(1.01-1.2)$ \\
\hline & $>6$ months & 1 & & 1 & \\
\hline
\end{tabular}

In relation to the appearance of $A D R s, 31.1 \%$ of the staff reported the presence of some of them, 63.7\% did not mention anything and 5.2\% answered do not know, no answer (DK/NO). Of the total of individuals who reported having suffered some ADR, the most frequent was diarrhoea with abdominal pain (33.9\%) followed by headache (10.1\%). A 69.6\% declared that despite having suffered ADRs, they did not stop taking their chemoprophylaxis, compared to the 9.4\% who said they did. Of the $30.5 \%$ who presented ADRs, 4.2\% received hospital healthcare, finding association only with the trip duration, the longer the stay the greater the appearance of ADRs.

No relationship was established between the occurrence of adverse reactions and the low adherence to treatment, because no statistically significant association was found, despite the fact that the personnel with low adherence presented a higher number of ADRs (66.2\%) than those who did not $(p=0.981)$. Personnel with reactions maintained good adherence (33.8\%).

Regarding the last objective, there was no relationship between the duration of the chemoprophylaxis and the increase in adverse reactions. The highest percentage of ADRs was presented by personnel who remained deployed between > 1 month and 4 months (14.7\%) compared to $4.2 \%$ of those who were deployed for more than 6 months, with a statistically sig-

oprophylaxis was Dakar (5.1\%); there are statistically significant association in both cases $(p<0.01)$.

In relation to the length of the deployment, the period in which the insect repellent was most used, was the one that ranged between $>1$ month and 4 months (38.0\%) and regarding the antimalarial chemoprophylaxis there were two periods with a significant impact, those who ranged between $>1$ month and 4 months and between $>4$ months and 6 months (6.3\% in both cases), there are statistically significant associations ( $p<0.01, p=0.03$ respectively).

In order to measure the adherence to the use of antimalarial chemoprophylaxis it was used the "Morisky- Green Test" $[13,14]$. Of the total of individuals who made up the sample, only $35.5 \%$ (95\% Cl: $28.8-42.2)$ showed good adherence to medication consumption, compared to $64.5 \%$ (95\% Cl: $57.8-$ 71.2), which did not. About the different factors that could influence the good adherence or not to chemoprophylaxis, the only statistically significant association was the country of deployment. The personnel that travelled to Dakar presented a higher percentage of adherence (10.7\% Cl95\%: 6.4-15.0) ( $p=$ 0.008). Likewise, a significant association was found between the personnel who consumed another type of medication with a good adherence to chemoprophylaxis (15.2\% Cl 95\%: 10.220.2) $(p=0.023)$ nificant association $(p=0.004)$.

Regarding the use of mosquito screens on window and mosquito net for bed, the variables significantly associated with a lower probability of adhesion are shown in table 3 . Those professionals with less active service were 1.87 (1.68-1.99) more likely not to use mosquito screens on window and mosquito net for bed 1.62 (1.55-1.69). Also, those with a lower level of education were more likely not to use mosquito screens on window 1.24 (1.07-1.42) and mosquito net for bed 1.37 (1.21-1.54). Army personnel were the most likely to not use mosquito screens on window 1.49 (1.34-1.64) and mosquito net for bed 1.43 (1.33-1.53). To conclude the shorter trip duration, more likely not to use the mosquito screens on window 1.36 ((1.211.52) and mosquito net for bed 1.68 (1.58-1.78).

\section{DISCUSSION}

The percentage of response was 36.9\%, lower than other studies conducted where it ranged between 100\% [14], 83.2\% [15] and 74\% [16], although similar to another study with $36.2 \%$ [17]. The reason could be the place where military personnel carry out their activity, sometimes outside their facilities with a difficult access to Internet. Another alternative method for completing the survey was not contemplated. Maybe in later studies the mobile will be used as a means to answer the survey. 
Not many differences were found between the responding group and the one that did not, except sex, perhaps there is no contact with the interviewee, rejection of the same, inability to cooperate (illness, language problems) or schedule difficulties.

In relation to the degree of compliance with the measures of individual protection, the use of air conditioner by the personnel of our Armed Forces was 93.8\%, only association being found at level of studies. No bibliography has been found that has studied the use of air conditioner in the rooms, perhaps it was not available in the rooms or they didn't use it as a preventive measure. The intensive use of air conditioner by staff could be triggered by the high temperatures in the deployment areas.

The percentage of use of mosquito screens on windows was $56.0 \%$, differences were found between education level, force belonging, country development a trip duration. Data similar to a study carried out in Saudi Arabia where the percentage was $47.3 \%$ [18]; but higher than the results of other studies, where the percentage ranged between $18.0 \%$ [15] and $19.7 \%$ [19]. The difference in use could be because the meshes were installed both in hotels and military bases where the staff of this study was housed and the rest of the results referred to non-military facilities.

In the present study, the mosquito net for beds was used by $34.0 \%$ of the personnel, differences were found between education level, force belonging, country development a trip duration. Similar data was found in another article carried out in Tibet, 35.0\% [16], but other studies have lower percentages $19.7 \%$ [20], 18.14\% [14] and 2.2\% [21]. The use could be due to the health advice received in the traveller's office and/or the use of facilities with a prior installation of nets.

An $85.8 \%$ used insect repellent on a regular basis, differences were found between education level, country development a trip duration. Our results were higher than other studies were the percentages ranged from $41.9 \%$ [17] to $32.2 \%$ [21]. There were also other studies with even lower percentages, oscillating between 16.8\% (2002), 15.0\% [20], 11.2\% (2007) [15] and 7.24\% [14]. This intensive use was perhaps a consequence of the insistence in the importance of this measure to avoid the bite of insects by the medical personnel and the health advice provided in the traveller's office.

Only 19.0\% of personnel reported the use of chemoprophylaxis, differences were found between country development and a trip duration. A very low figure if we compare it with other studies where 82.1\% [15] took antimalarial tablets. The reason for this behaviour could be related to the appearance of ADRs. The staff used more chemoprophylaxis depending the country of deployment, especially if they were African countries and if the length of the deployment was between 1 and 6 months. It could be that longer periods favour the feeling of immunity in the staff or the fear of adverse reactions. On the other hand, it could be than the staff believes that, a short stay, could reduce or avoid the probability of mosquitoes' bite.
A 31.1\% showed the presence of ADRs, in the present study. Data very similar to others where the percentage was $32.2 \%$ [21], 24\% [23] or 25\% [15] corresponding to those reflected in the drug's technical data sheet [12]. Once established that it was not the appearance of ADRs one of the causes of low staff adherence, perhaps the reduction was related to the intensive use of repellents. The general protection measures against malaria were met in high percentage, while the use of chemoprophylaxis was very low. These epidemiological data allowed us to know the validity of the health education that is provided in the traveller's office care consultation. It also allowed being aware of the possibilities of infection and import of malaria by personnel of the Spanish Armed Forces. The traveller's office will reinforce the importance of taking the adequate chemoprophylaxis trough conferences and informative diptychs.

The most important limitation of this study refers to the sample. Also, another limitation of this study was the low response rate obtained, although higher than the sample size calculated. Likewise, if a sample size calculation had been made with a 5\% error rate and a 95\% confidence level and an expected loss ratio of $30 \%$, the number of individuals should have been 210 versus 194 that formed the study. Selection through a probabilistic sampling stratified by gender should have included 193 males (194 were included) and 17 females (none were included). There was no female answer data available. Perhaps, most of the personnel who answered did it because they mostly complied with the measures of individual protection, against those who did not comply and were reluctant to answer. The external validity of this study is not very high due to its limitation. To improve adherence to chemoprophylaxis, health education measures should be implemented such as conferences, delivery of leaflets or use of mobile apps.

The personnel protection is essential to safeguard the health of the individual, the group and national public health upon return. Measures of general protection against malaria were met in a high percentage of cases, except the use of antimalarial chemoprophylaxis. The degree of compliance with the use of air conditioner, mosquito screens for windows and insect repellent of our Armed Forces was very high. The use of chemoprophylaxis was very low (19.0\%) nevertheless the staff used more chemoprophylaxis if were deployed in African countries and if the length of the deployment was between 1 and 6 months. Only $31.1 \%$ showed the presence of ADRs, but this was not one of the causes of low staff adherence. The health education provided in the traveller's office care consultation is valid but there must be reinforced the importance of taking the adequate chemoprophylaxis. Therefore, it is necessary to change and reorient the current health education.

\section{FUNDING}

None to declare. 


\section{CONFLICTS OF INTEREST}

The authors declare that they have no conflicts of interest.

\section{REFERENCES}

1. Miller $E_{1}$ Dushoff J HA. The risk of incomplete personal protection coverage in vector-borne disease. J R Soc. Interface. 2016;13(115). Doi: 10.1098/rsif.2015.0666.

2. Stringer C, Chiodini J, Zuckerman J. International travel and health. WHO Library Cataloguing-in-Publication Data. 2012.

3. WHO. World Malaria Report. World Health Organization. 2016: 1-186. https://www.who.int/malaria/publications/world-malaria-report-2016/report/en/ [Accessed 10 January 2018]

4. Goodyer L, Rice L, Martin A. Choice of and adherence to prophylactic antimalarials. J Travel Med.2011;18(4):245-9. Doi: 10.1111/j.1708-8305.2011.00534.x.

5. Mayet A, Lacassagne $D$, Juzan N, Chaudier B, Haus-Cheymol R, Berger $F$, et al. Malaria outbreak among french army troops returning from the Ivory Coast. J Travel Med. 2010;17(5):353-5. Doi: 10.1111/j.1708-8305.2010.00437.x.

6. Kersgard CM, Hickey PW. Adult malaria chemoprophylaxis prescribing patterns in the military health system from 2007-2011. Am J Trop Med Hyg. 2013;89(2):317-25.

7. López-Vélez R de GM. Cuaderno de Malaria importada. Cuaderno 2. Prevención en viajes. España; 2009.

8. Nakato H, Vivancos R, Hunter PR. A systematic review and meta-analysis of the effectiveness and safety of atovaquone Proguanil (Atovaquone-Proguanil) for chemoprophylaxis against malaria. J Antimicrob Chemother. 2007;60(5):929-36.

9. Kato T, Okuda J, Ide D, Amano K, Takei Y, Yamaguchi Y. Questionnaire-based analysis of atovaquone-proguanil compared with mefloquine in the chemoprophylaxis of malaria in non-immune Japanese travelers. J Infect Chemother. 2013;19(1):20-3. Doi: 10.1007/ s10156-012-0446-z

10. Leshem E, Meltzer E, Stienlauf S, Kopel E, Schwartz E. Effectiveness of short prophylactic course of atovaquone-proguanil in travelers to sub-Saharan Africa. J Travel Med. 2014;21(2):82-5. Doi: 10.1111/jtm.12088.

11. Atovaquone-Proguanil F técnica. Ficha técnica AtovaquoneProguanil. Madrid: GlaxoSmithKline; 2016. p. 1-12.

12. Stringer $C$, Chiodini J, Zuckerman J. International travel and health. WHO Library Cataloguing in Publication Data. 2019. https://www. who.int/ith/ith-country-list-new.pdf [Accessed 2 February2018]

13. Morisky DE, Green LW, Levine D. Concurrent and predictive validity of a self-reported measure of medication adherence. Medical Care. 1986;24(1):67-74. Doi: 10.1097/00005650-198601000-00007

14. Morisky DE, Green LW, Levine D, Green L, Shapiro BS, Patterson Russell MD, Smith Craigh R. Five-year blood pressure control and mortality following health education for hypertensive patients. AJPH. 1983; 73(2):153-162.

15. Imtiaz F, Nisar N, Shafi K, Nawab F. Knowledge and Practices Re- garding Malaria Control and its Treatment among Patients Visiting Outpatient Clinics of Civil Hospital Khairpur. Ash Kmdc. 2015;21(4):221-7.

16. Peragallo MS, Sarnicola G, Boccolini D, Romi R, Mammana G. Risk assessment and prevention of malaria among Italian troops in Afghanistan, 2002 to 2011. J Travel Med. 2014;21(1):24-32. Doi: 10.1111/jtm. 12046 .

17. Nicosia $V_{1}$ Colombo G, Consentino M, Di Matteo $S_{1}$ Mika $F_{1}$ De

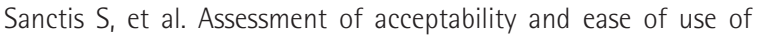
atovaquone/proguanil medication in subjects undergoing malaria prophylaxis. Ther Clin Risk Manag. 2008;4(5):1105-10. Doi: 10.2147/tcrm.s3782

18. Liu X, Wan F, Bai L. Community Knowledge and Experience of Mosquitoes and Personal Prevention and Control Practices in Lhasa, Tibet. 2014;9919-37. Doi: 10.3390/ijerph110909919.

19. Khairy S, Al-Surimi K, Ali A, Shubily HM, Al Walaan N, Househ $M$, et al. Knowledge, attitude and practice about malaria in south-western Saudi Arabia: A household-based cross-sectional survey. J Infect Public Health. 2017;10(5):499-506. Doi: 10.1016/j. jiph.2016.09.021

20. Al Abri SS, Abdel Hady DM, Al Abaidani IS. Knowledge, attitudes, and practices regarding travel health among Muscat International Airport travelers in Oman: Identifying the gaps and addressing the challenges. J Epidemiol Glob Health. 2016;6(2):67-75. Doi: 10.1016/j.jegh.2016.02.003

21. Alobuia WM, Missikpode C, Aung M, Jolly PE. Knowledge, Attitude, and Practices Regarding Vector-borne Diseases in Western Jamaica. Ann Glob Health. 2015;81(5):654-63. Doi: 10.1016/j. aogh.2015.08.013.

22. Anand T, Kumar R, Saini V, Meena GS and IG. Knowledge and Use of Personal Protective Measures Against Mosquito Borne Diseases in a Resettlement Colony of Delhi. Ann Med Heal Sci Res. 2014;4(2):227-32. Doi: 10.4103/2141-9248.129048

23. Nicolas B, Charbonnie P. Évaluation de I' observance d ' une chimioprophylaxie antipaludique dans un équipage de la Marine nationale en déploiement en Asie du Sud-Est Assessment of adherence to malaria chemoprophylaxis in a French Navy frigate deployed in Southeast Asia. Med Sante Trop. 2017;155-9. Doi: 10.1684/ mst.2017.0666 